\title{
Article \\ Adoption of Green Building Assessment Systems to Existing Buildings under Kazakhstani Conditions
}

\author{
Alexey Remizov, Aizhan Tukaziban, Zhuldyz Yelzhanova, Tokzhan Junussova and Ferhat Karaca * $\mathbb{D}$ \\ Civil and Environmental Engineering Department, School of Engineering and Digital Sciences, Nazarbayev \\ University, Astana 010000, Kazakhstan; alexey.remizov@nu.edu.kz (A.R.); aizhan.tukaziban@nu.edu.kz (A.T.); \\ zhuldyz.yelzhanova@nu.edu.kz (Z.Y.); tokzhan.junussova@nu.edu.kz (T.J.) \\ * Correspondence: ferhat.karaca@nu.edu.kz
}

Citation: Remizov, A.; Tukaziban, A.; Yelzhanova, Z.; Junussova, T.; Karaca, F. Adoption of Green Building Assessment Systems to Existing Buildings under Kazakhstan Conditions. Buildings 2021, 11, 325. https://doi.org/10.3390/ buildings 11080325

Academic Editor: Wahidul Biswas

Received: 15 June 2021

Accepted: 23 July 2021

Published: 28 July 2021

Publisher's Note: MDPI stays neutral with regard to jurisdictional claims in published maps and institutional affiliations.

Copyright: (c) 2021 by the authors. Licensee MDPI, Basel, Switzerland. This article is an open access article distributed under the terms and conditions of the Creative Commons Attribution (CC BY) license (https:// creativecommons.org/licenses/by/ $4.0 /)$.
Abstract: The construction industry is an enormous economic sector with a profound economic, social, and environmental impact. The building sector is responsible for one-third of total energy consumption and, notably, construction activities account for $39 \%$ of the total carbon emissions in the world. Therefore, nowadays, the promotion of green building concepts is essential for all countries. Typically, the sustainability level of a building is evaluated by specified certification systems through rating assessment tools. The development of national assessment tools is necessary for the developing world due to environmental, social, and economic issues; consequently, a national assessment tool adopted under specific local conditions would provide a more precise assessment. This paper analyzes the rating system of BREEAM, LEED, CASBEE, and Green Globes certification systems and discusses their adoption with assessment measures for the existing buildings in Kazakhstan's reality. The following main criteria were discussed during six roundtable sessions: sustainable site and landscape, energy and carbon footprint reduction, water and wastewater management, indoor environmental quality, sustainable building materials, commissioning, and maintenance. A set of assessment criteria and measures were suggested, and 43 existing buildings were assessed. Only eight buildings reached a high rating level. The "sustainable site and landscape" and "indoor environmental air quality" categories were the categories with the highest scores; otherwise, "energy and carbon footprint reduction" with "water and wastewater management" had the lowest average scores. One of the buildings was evaluated separately by several experts to check the consistency of the suggested assessment measures. This evaluation also provided insight into how the assessors' knowledge and experience may change the overall rating scores obtained. The most critical issues for the existing buildings in Kazakhstan's reality were discussed. Despite the widespread adoption of green certification methodology, the application of global certification systems in Kazakhstan remains complicated due to the lack of knowledge and limited awareness.

Keywords: sustainability; green buildings; certification systems; assessment tools; central Asia

\section{Introduction}

The construction sector of industry plays an essential role in a country's economic, environmental, and social aspects. It directly promotes the urbanization process and affects economic growth. The development of the construction industry offers advantageous influences by providing buildings to provide better and safer conditions by improving the work/life spaces for people. In the case of Kazakhstan, the construction industry is considered an attractive investment area. The sector accounts for up to $6 \%$ of the gross domestic product (GDP) in Kazakhstan and offers more than 700 thousand jobs [1].

However, the construction process is accompanied by adverse effects. Noise and traffic congestion are the comparatively slight inconveniences caused by construction activities. The main serious problem that is induced by construction activities is environmental pollution. The construction sector is one of the largest resource consumers, with half of 
them being non-renewable. The industry consumes $40 \%$ of the world's raw stone, gravel, and sand, and $25 \%$ of virgin wood per year [2].

According to the World Green Building Council's report from 2017, construction accounts for $39 \%$ of the total carbon emissions globally; $28 \%$ of it is caused by operational emissions such as energy usage for heating, cooling, and lighting. The other $11 \%$ are caused by embodied carbon emissions from the materials and construction processes throughout the whole building's lifecycle. By 2025, the carbon emission caused by buildings and construction will be higher by $43 \%$ compared with 2007 [3].

The severe weather conditions in Kazakhstan necessitate the high energy consumption of residential buildings [4]. In the entire building sector, residential and commercial buildings account for 30\% of energy consumption [1]. Moreover, in Kazakhstan, in 2020, the volume of waste products has grown by $3.6 \%$ compared with 2019 [5]. This is explained by the dynamic development of economic sectors, an increase in the capacities of existing ones, and the commissioning of new enterprises. However, it does not deny that the construction process induces huge losses/damage to the environment. The country has promising potential from alternative energy sources, specifically from solar, wind, hydro, and biomass; however, these contribute less than $1 \%$ of the total energy resources [5]. It is also crucial to promote the green building concept.

There is no exact definition for green buildings. According to the World GBC, a green building is "a building that aims to minimize the adverse effects of the surrounding environment and natural resources during the construction stage and the whole lifecycle of the structure." The green building concept deals with carbon footprint reduction, energy-savings, environmental pollution issues, and economic and social aspects of sustainable development [6]. In general, green buildings are energy-efficient, water-conserving, durable, and non-toxic structures, with a recycled material content as high as possible [7]. Together with positively impacting the occupants' health and the environment in total, green buildings reduce operating costs, promote building and organizational marketability, and improve the occupier's health and productivity [8].

Specialized rating systems typically evaluate the performance of green buildings. One of the earliest established assessment tools is the Building Research Establishment Environmental Assessment Method (BREEAM), developed in the United Kingdom in 1990. It defines standards for the environmental performance of buildings in the design, construction, and operation stages. BREEAM has assessed almost 550,000 buildings in 70 countries worldwide [9]. As a limitation of the BREEAM certification system, its static assessment approach might be mentioned, which is not applicable for sharply developing objects. Its criteria are not suitable for the long-term assessment of dynamic development. All these factors make the system difficult to adopt under local conditions [10]. Leadership in Energy and Environmental Design (LEED) is another conventional tool established in 1998 and developed by the United States Green Building Council (USGBC). LEED is a certification system that verifies that a building was designed and constructed using strategies to improve performance across all the metrics that matter most: energy savings, water efficiency, $\mathrm{CO}_{2}$ emission reductions, improved indoor environmental quality, stewardship of resources, and sensitivity to their impacts. It has been applied in almost 135 countries worldwide [11]. Regarding the disadvantages of LEED over other certification systems, it was pointed that its criteria do not strongly correspond to measurable environmental impacts compared with other certification systems. Moreover, it would be better if the criteria's underlying sustainability goals were pointed out [12]. Several assessment tools rate the sustainability level of a building or community. Such assessment tools are necessary for the developing world due to the environmental, social, and economic issues. Each certification system has limitations, since it cannot consider all factors, while each region has unique conditions and environment. Thus, developing a country-specific (e.g., Kazakhstani) sustainability evaluating tool that considers all local environmental, economic, and social features is becoming a priority task. 
This study analyzed the components of existing assessment tools and examined their potential applicability in Kazakhstan's case. It used structured workshops and roundtable discussions to assess the criteria and evaluate their usability in the selected context. It also suggested the optimum criteria set and measures by addressing how they should be modified. This provided early insights and ideas to develop a country-specific adjustment of Kazakhstan's green building assessment criteria, contributing to developing a national Green Building Certification System. The study is structured in five sections. Section 2 is dedicated to a description of the system components, Section 3 evaluates the performance indicators. The practical framework is discussed in Section 4. The results of the literature analysis and research conclusion are presented in Section 5.

\section{Methodology}

Under the project's scope, the research aimed to provide the necessary knowledge for developing a structured green building certification assessment for Kazakhstan. The methodology part is organized as follows (Figure 1). The first subsection involved a thorough research of the protocols, rating systems, and guidance of BREEAM, LEED, CASBEE, and Green Globes certificates. Those green building rating systems were chosen due to their predominant ranking system status in the certification systems of 12 countries included in the world green building council [13]. The following subsection includes a description of workshops based on existing certificates. The final certification created is discussed in Section 3.

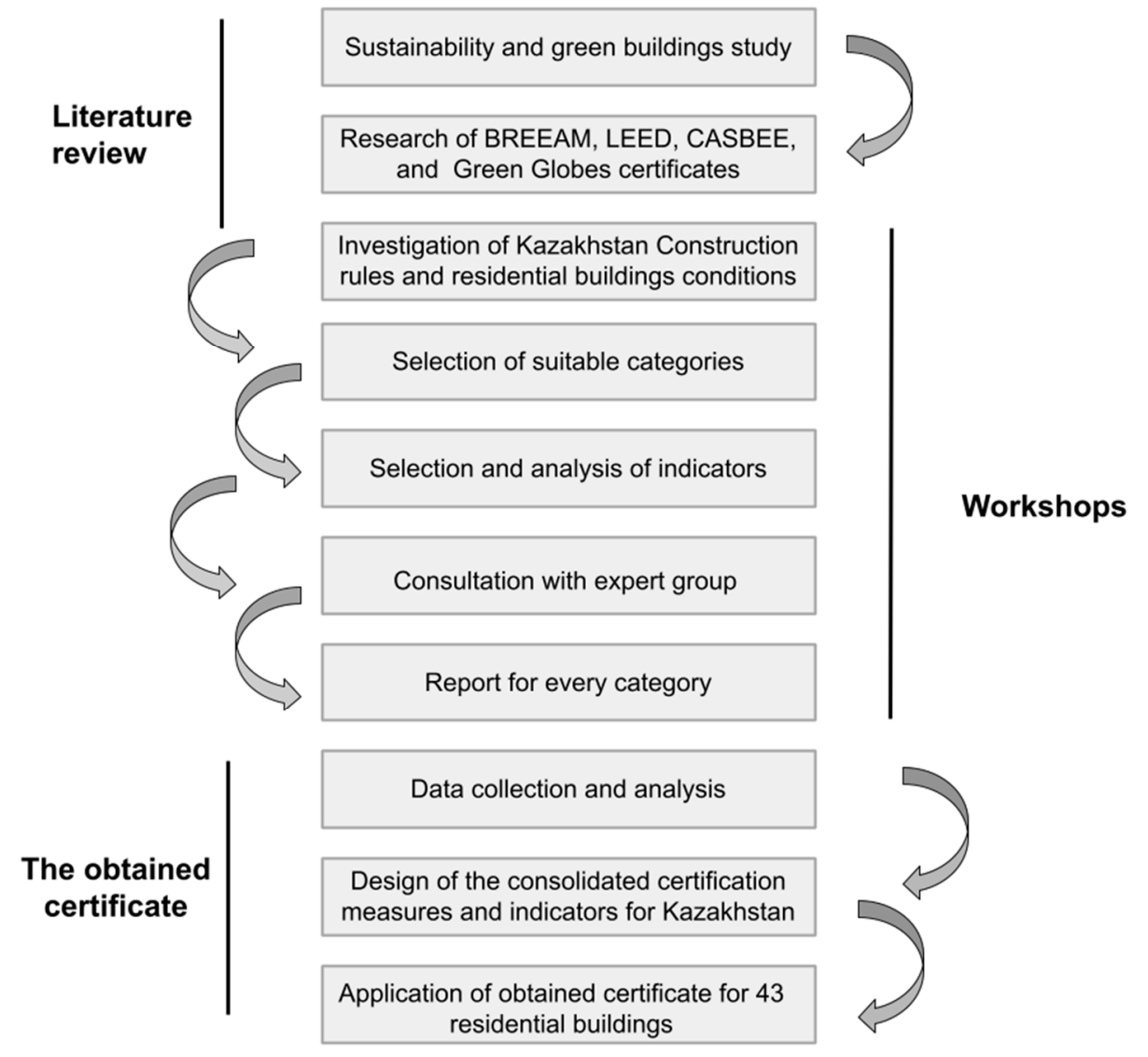

Figure 1. Organization of the methodology.

\subsection{Investigation of Existing Certificates}

Certification systems are commonly used to assess sustainability [14]. Four worldleading protocols were researched and analyzed to develop a green building assessment methodology for KZ. The selected certification systems assess sustainability at various stages of construction, as follows: 
- BREEAM-The protocol is divided into 9 macro-zones; $10 \%$ extra points can be gotten for "innovation credit." It has such 6 rating levels based on the final score: unclassified (less than 30$)$, pass $(\geq 30$ p.), good ( $\geq 45$ p.), very good ( $\geq 55$ p.), excellent $(\geq 70$ p.), and outstanding ( $\geq 85$ p.) [15-17].

- LEED-The certificate includes nine main areas, which consider critical aspects of sustainable buildings. The protocol has a rating system with 100 maximum points and 10 additional points earned in categories such as "innovation" and "regional priority." There are four levels of the protocol certification, depending on the number of obtained points: no classification (less than 40 ), certified (40-49 p.), silver (50-59 p.), gold (60-79 p.), and platinum ( $\geq 80$ p.) $[11,16,18]$.

- CASBEE-Its final score is earned based on the relationship between the living conditions inside the building ("building environmental quality and performance") and the environmental impact of the building ("building environmental loadings"). The rating system consists of 6 levels: poor $(<0.5)$, fairly poor $(0.5-1$ p.), good (1-1.5), very good (1.5-3 p.), and excellent $(\geq 3$ p.) [16,19].

- Green Globes-This is a protocol that allows building owners to select elements of sustainability. The scoring is based on a 22-page online questionnaire, which covers eight areas. The Green Globes rating level includes 1 Globe (35-54\%), 2 Globes (55-69\%), 3 Globes (70-84\%), and 4 Globes (85-100\%) [20,21].

\subsection{Workshops}

The way the workshops were organized was as follows. Twenty-four experts with an above Master's degree in Civil and Electrical Engineering and a clear interest in the topic of green buildings were chosen to investigate and develop a certificate for Kazakhstan. The number of experts was not set initially; this was the number of experts available during the workshops; it could be fewer or more, and no prior decision was made on the number of experts. First of all, the specialists were divided into 6 groups. Next, every team researched the chosen category and prepared a presentation. The workshop included discussions, which were conducted 3 hours per week for 6 months, accompanied by written reports.

The aim of the workshop was to select suitable categories for Kazakhstan. After an extensive study of certifications, and consultation with academics and engineers, 6 basic categories were chosen. These 6 categories were the main categories mentioned in the certification systems $[15,19,20,22]$ : sustainable site and landscape, energy and carbon footprint reduction, water and wastewater Management, indoor environmental quality, sustainable building materials, and commissioning and maintenance.

The indicators of every category were researched through following questions. Firstly, "Is this topic relevant for Kazakhstan's residential and commercial buildings?" Secondly, "Does the country have experience in the topic?" Finally, we considered the possible innovations in construction which will be implemented in the future. Thus, each topic was studied during 1 week and evaluated by 24 green building experts; they all have civil and environmental engineering backgrounds at various graduate levels from Master's to PhD. Next, there was a consolidation stage.

The primary research material consisted of the data collected and analyzed. Weighted factor scoring was used to assess the relevance and significance of each category and optimization of the obtained certification. Each area was assumed to be of different importance in the scoring system. One to 10 points were awarded through voting by experts, where 1 is not an essential category for Kazakhstan and 10 is the highest importance. Consequently, some categories were assigned more points (more critical): energy and carbon footprint reduction, indoor environmental quality, and sustainable building materials. The other categories were assigned fewer points (see Table 1, Column 2: Weights). 
Table 1. Criteria, scores, and weights obtained for the selected factors in green building certification.

\begin{tabular}{|c|c|c|c|c|c|}
\hline Total Score & Weights & Factors & Points Awarded & Subcategories & Points \\
\hline \multirow[t]{31}{*}{100} & 0.151 & $\begin{array}{l}\text { Category } 1 \text { : Sustainable site } \\
\text { and landscape } \\
\text { (max. } 100 \text { points) }\end{array}$ & 100 & Effect of building on the site's environment & 20 \\
\hline & & & & Greenfields, brownfields, and floodplains & 20 \\
\hline & & & & Rainwater management & 20 \\
\hline & & & & Social wellbeing & 20 \\
\hline & & & & Construction activity pollution prevention & 20 \\
\hline & 0.184 & $\begin{array}{l}\text { Category 2: Energy and } \\
\text { carbon footprint reduction } \\
\text { (max. } 100 \text { points) }\end{array}$ & 100 & Reduction of energy use & 30 \\
\hline & & & & Reduction of carbon emissions & 15 \\
\hline & & & & HVAC & 20 \\
\hline & & & & Renewable energy & 15 \\
\hline & & & & Lighting & 20 \\
\hline & 0.162 & $\begin{array}{l}\text { Category 3: Water and } \\
\text { wastewater management } \\
\text { (max. } 100 \text { points) }\end{array}$ & 100 & Water use monitoring & 20 \\
\hline & & & & Water quality management and treatment & 20 \\
\hline & & & & Wastewater management & 20 \\
\hline & & & & Water-efficient equipment and reduction & 20 \\
\hline & & & & Alternative sources of water & 20 \\
\hline & 0.171 & $\begin{array}{l}\text { Category 4: Indoor } \\
\text { environmental quality } \\
\text { (max. } 100 \text { points) }\end{array}$ & 100 & Thermal comfort & 22 \\
\hline & & & & Indoor air quality & 22 \\
\hline & & & & Safety requirements & 22 \\
\hline & & & & Acoustic comfort design & 17 \\
\hline & & & & Interior lighting design & 17 \\
\hline & 0.176 & $\begin{array}{l}\text { Category 5: Sustainable } \\
\text { building materials }\end{array}$ & 100 & Interior materials & 8 \\
\hline & & & & Exterior materials & 8 \\
\hline & & & & Waste & 25 \\
\hline & & & & Building envelope & 42 \\
\hline & & & & Resource conservation & 8 \\
\hline & & & & Building service life plan & 8 \\
\hline & 0.156 & $\begin{array}{l}\text { Category 6: Commissioning } \\
\text { and maintenance } \\
\text { (max. } 145 \text { points) }\end{array}$ & 100 & Operations and maintenance training & 28 \\
\hline & & & & Aftercare & 17 \\
\hline & & & & $\begin{array}{l}\text { Environmental management system (EMS) } \\
\text { and documentation }\end{array}$ & 11 \\
\hline & & & & Commissioning & 33 \\
\hline & & & & $\begin{array}{l}\text { Regular review and management plans and } \\
\text { programs }\end{array}$ & 11 \\
\hline
\end{tabular}

\section{Results of the Consolidated Certification Measures and Indicators for Kazakhstan}

The assessment system should work by answering the questions of the indicators or checking how well the object corresponded to them. The next step was summing up the scores obtained and getting the final score in a range from 0 to 100 , where 0 is the lowest and 100 is the highest rating, measuring the percentage of compliance with the assessment 
criteria. Table 1 demonstrates the obtained criteria, scores, and weights for the selected factors in green building certification.

\subsection{Sustainable Site and Landscape}

The construction of buildings on well-designed sustainable sites and landscapes is crucial, and the weight of this category is equally important as other categories. The well-developed sustainable site and landscape provide a variety of benefits such as: improving and keeping biodiversity and ecosystems safe, enhancing water and air quality, waste reduction, and improving the wellbeing of occupants. These subcategories have been selected as the most relevant for further assessment system development: effect of building on the site's environment; greenfields, brownfields, and floodplains; rainwater management; social wellbeing; and construction activity-pollution prevention.

\subsection{Energy and Carbon Footprint Reduction}

At present, the world's population is constantly growing; along with this, the production and consumption of energy and carbon dioxide emissions into the atmosphere are growing. Buildings and industry consume the most energy. It is necessary to change the structure of energy production, involving some amount of renewable energy in the energy production structure. Consequently, sustainable buildings with reduced energy consumption are a solution. The construction of green buildings leads to a decrease in pollution. This category includes subcategories such as reduction of energy use, reduction of carbon emissions, HVAC, renewable energy, and lighting.

\subsection{Water and Wastewater Management}

Water is one of the most valuable natural resources and is vital to the economy. Kazakhstan is one of the countries of the Eurasian continent with a very significant water shortage. The average consumption of water for domestic and drinking needs is about $170 \mathrm{~L}$ per capita per day in urban areas and at approximately $70 \mathrm{~L}$ per capita per day in rural areas [23]. For this reason, sound water consumption and wastewater management systems are essential. The chosen subcategories are water use monitoring, water quality management and treatment, wastewater management, water-efficient equipment and reduction, and alternative water sources.

\subsection{Indoor Environmental Quality}

This criterion is essential, since ordinary people spend about $90 \%$ of their time indoors, which directly influences human health. The category is divided into five critical subcategories to simplify the structure of the assessment tool: thermal comfort, indoor air quality and safety requirements, acoustic comfort, design and interior, and lighting design.

\subsection{Sustainable Building Materials}

The meaning of a sustainable material is that it has an insignificant effect on the environment during its operation. Choosing green building materials is a daunting task for engineers and designers. The reason for this is that the diversity of building materials leads to complicated evaluations. In order to have a clearer picture of the assessment procedure, several subcategories of "sustainable building materials" were considered: interior materials, exterior materials, waste, building envelope, resource conservation, and building service life plan.

\subsection{Commissioning and Maintenance}

The commissioning and maintenance category is an important criterion. The category is divided into five essential subcategories: regular review and managing plans and programs, document control, preventive maintenance and regular cleaning programs, operations and maintenance training, and aftercare. 


\section{Results of Case Studies}

\subsection{Number of Samples, Geography, Buildings, Ages, and Types}

As a result of the work carried out by the green building experts, 43 existing buildings were assessed. The geography of the evaluated buildings is representative of the cities of Kazakhstan (Nur-Sultan, Almaty, Aktobe, Pavlodar, Taraz, Aktau, Zheskazgan, and Uralsk). The list included buildings from newly built to those that have been in operation for about 40 years. The average age of the buildings under study was eight years (Figure 1), and the architectural type of the buildings was identified during the assessments. Eighteen of the assessed buildings are new businesses/elite buildings, which is the most common type. The building type distribution histogram is summarized in Figure 2.

a.Building age

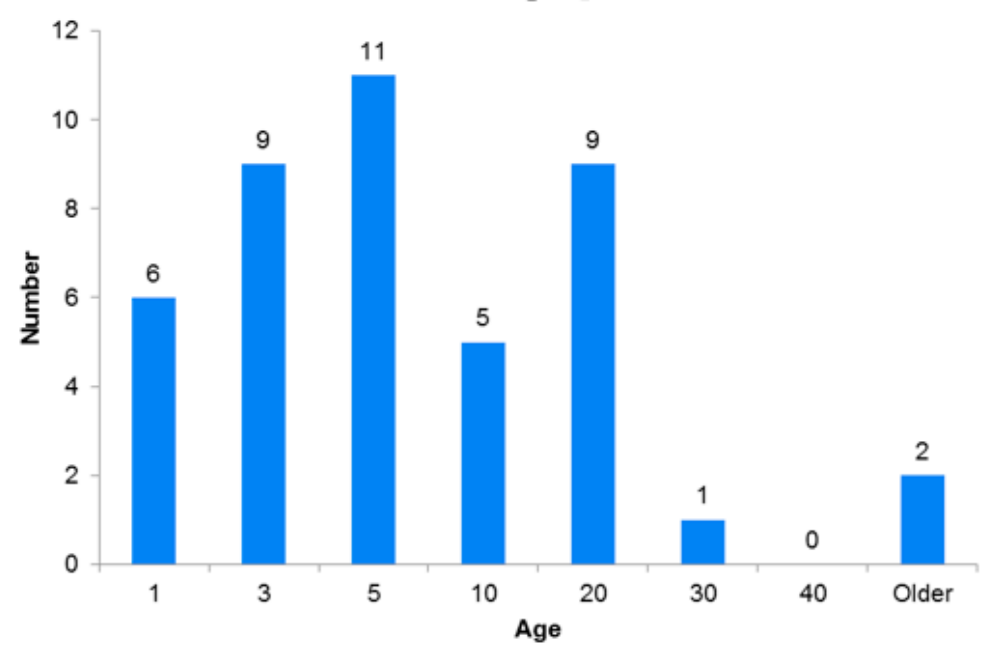

\section{b. Building types distribution}

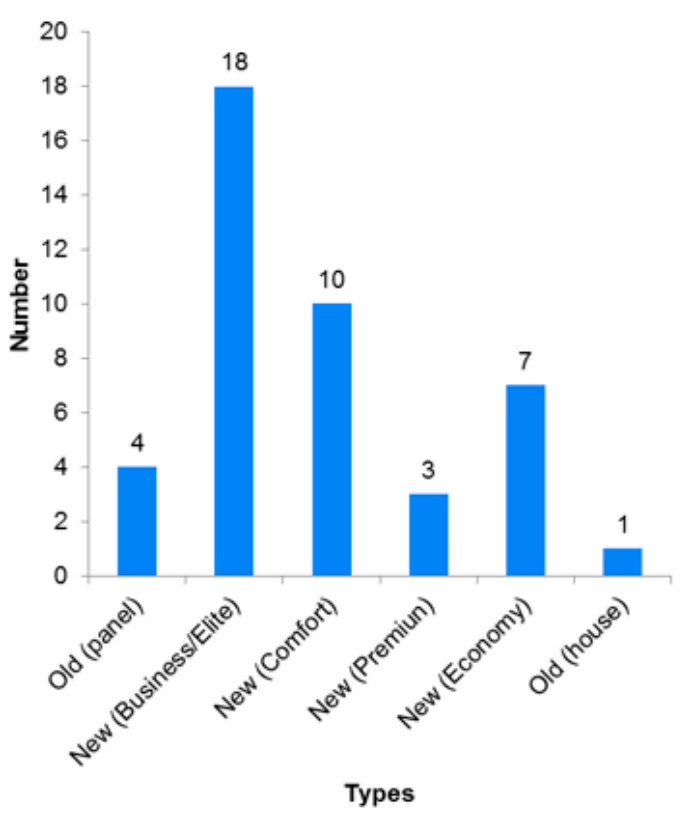

Figure 2. (a) Building age distribution histogram; (b) building type distribution.

Additionally, it is worth noting that two of the assessed buildings in the current study have successfully already been certified by international green building standards. Moreover, intentionally, one of the buildings was evaluated separately and studied by different experts to see the impact of the assessors' knowledge and experiences on the proposed criteria; this helped to judge how robust the set criteria assess and provide better judgments on the quality of the suggested assessment tool.

\subsection{Analysis of Categories and Total Scores}

The overall score is formed from the scores of the categories and subcategories. Each category has a weight, and some categories, being more important than others, have a more significant impact on the final score. Figure 3 shows the average scores for each category.

It can be seen that Category 1 "sustainable site and landscape" and Category 4 "indoor environmental air quality" have an average score of about 55, being the most highly rated categories. This variation may be because of the relatively high national construction and design standards; e.g., in Kazakhstan, there are high urban planning requirements. In general, urban development is carried out and regulated following detailed development plans. In addition, special attention is paid to the management of rainwater. Besides, in recent years, the country has introduced stringent construction activity pollution prevention standards. These measures make it possible to receive a high average score in the "sustainable site and landscape" category. National standards also forced the "indoor environmental air quality" category to be in the lead. Kazakhstan is a country with challenging 
climatic conditions; high thermal comfort and ventilation requirements are applied to all buildings in the country.

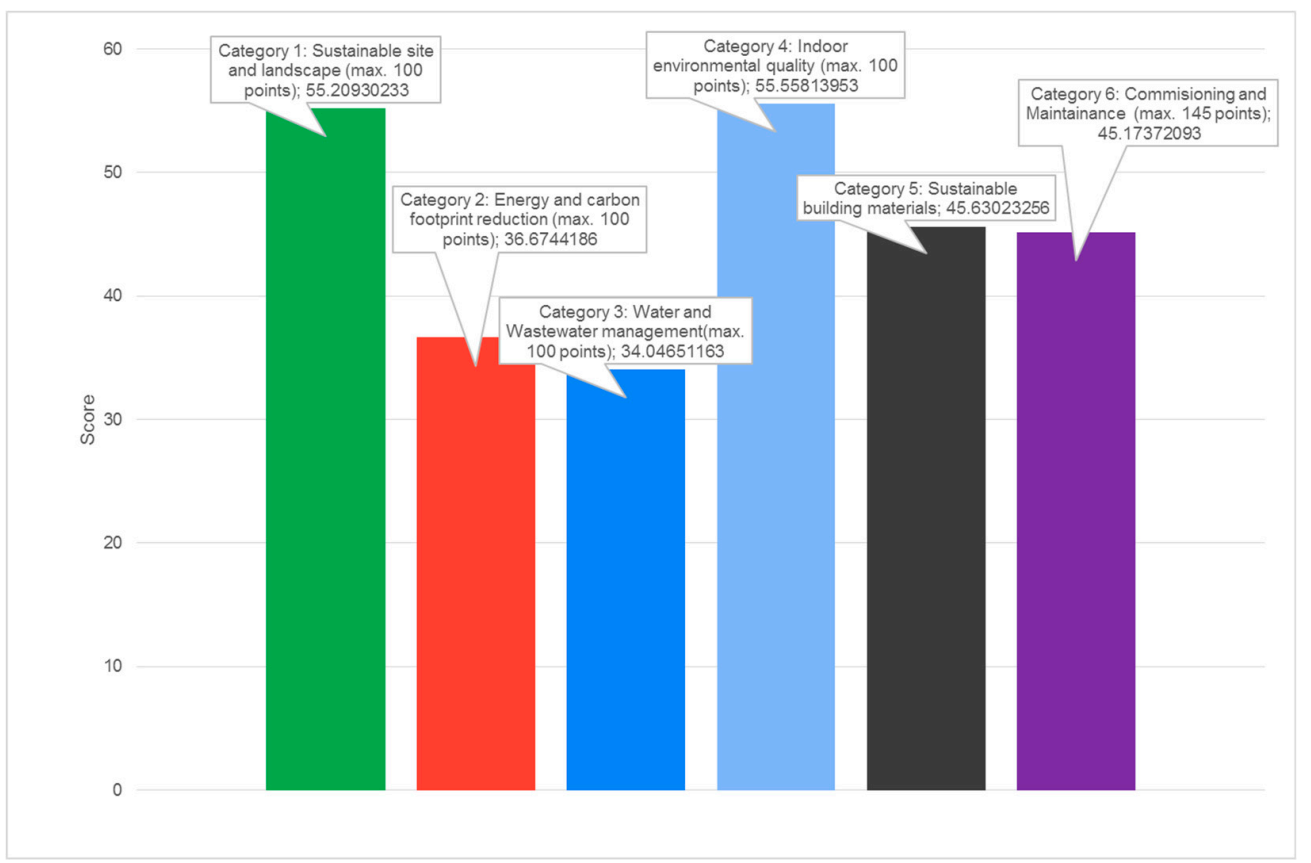

Figure 3. The average scores for each category.

On the other hand, Category 2 "energy and carbon footprint reduction" and Category 3 "water and wastewater management" have the lowest average scores, about 34 points. In our opinion, this was due to several key factors. The first is the low cost of electricity and energy overall. The energy price in Kazakhstan remains one of the lowest in the world. Electricity prices are USD $\$ 0.07$ per $\mathrm{kWh}$ for private consumers and USD $\$ 0.05$ for the industrial sector. The average electricity rate in the USA, for example, is USD $\$ 0.13$ per $\mathrm{kWh}$. In Singapore, the price of electricity is USD $\$ 0.19$ for households and USD $\$ 0.16$ for businesses; under such conditions, energy saving looks senseless to the users. Energy-saving technologies are gradually being introduced in Kazakhstan, but they do not bring significant economic benefits and are purely nominal. Second, concerning water and wastewater management, the situation is about the same. The cost of water is low; it is available in sufficient quantities for almost the entire population of the republic. Saving water and saving energy do not seem necessary and economically beneficial. It is also necessary to add that the quality of potable water in the republic can be considered high, but it falls short of the standards of Western countries, which is also reflected by Kazakhstan's low standards.

The final building scores (43) are summarized in Figure 4. The average total score is 46.17 points, the maximum is 76.90 points, and the minimum is 16.54 . A final score above 60 points can be considered high, and a building like this is outstanding for Kazakhstan's "green building" characteristics. Only eight buildings were rated above 60 points.

\subsection{Discussion: Assessment Tool Validation}

In order to verify the accuracy of the scores obtained using our assessment tool, it is necessary to verify it. A solution to this problem is to compare the obtained results with a standard or a reference. A building that has passed the certification procedure can serve as such a reference. In our study, two certified buildings located in Nur-Sultan were also assessed. Building Complex I was certified in 2016 by the LEED 2009 Existing Buildings Operations and Maintenance system. It has 53 points out of 110 and a silver certification level. This building received 51.8 points in our assessment tool, which is 
quite comparable with the reference value. Our assessment also showed similar results to the referenced building within the categories. For example, the "sustainable site and landscape" category received the highest number of points during the LEED certification; this category was also rated higher than the rest in our assessment. In the same way, the "water and wastewater management" category received the lowest score in our assessment and in the LEED certification.

\section{The final building 's scores by building type}

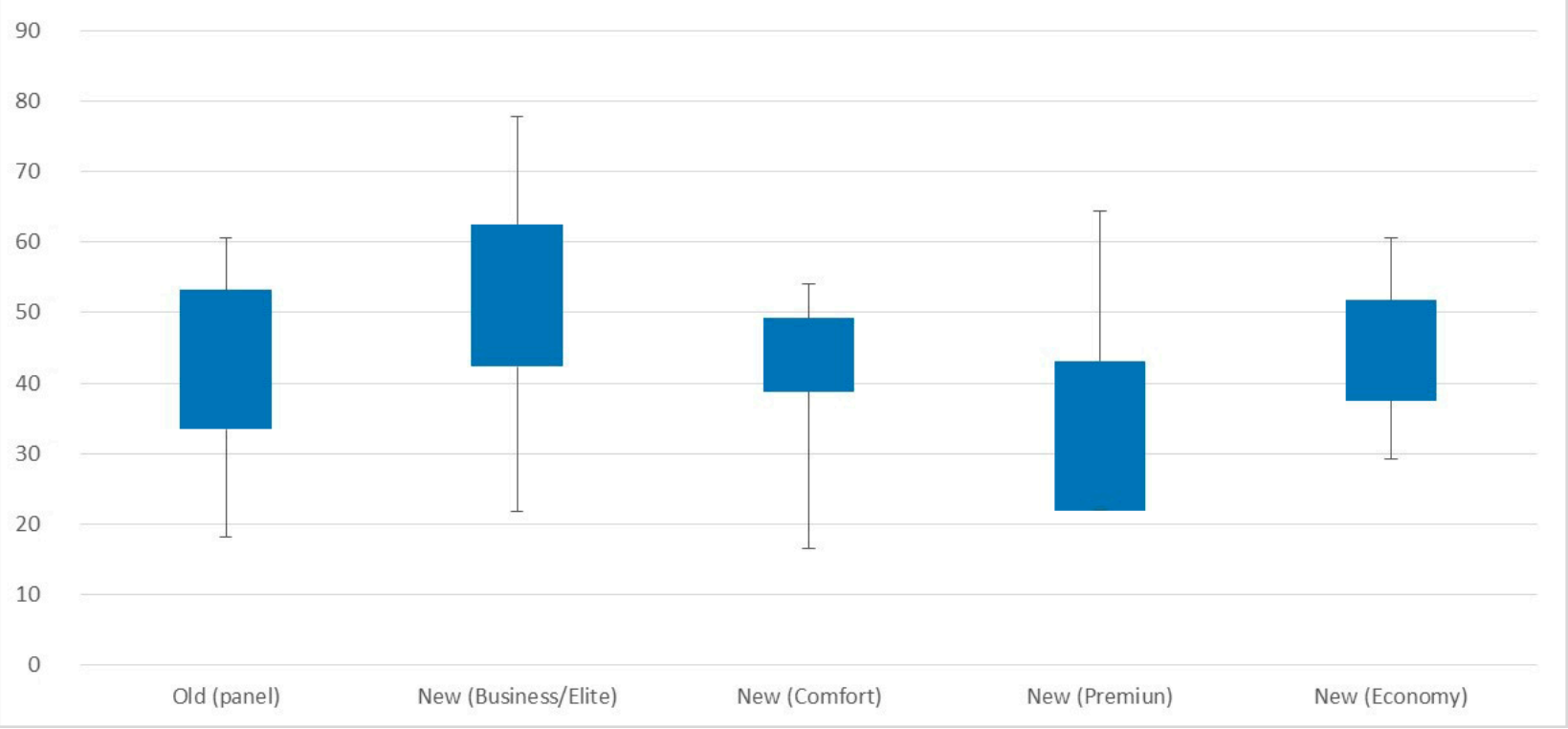

Figure 4. The final building's scores.

Building Complex II is a multifunctional complex that was also certified by LEED in the Core and Shell system. The certification year was 2018. It has 70 points out of 110 and a gold certification level. Our assessment ended in 76.9 points, comparable with the similar results of the reference within the categories. Of course, two cases are not enough for a confident validation of the performance and accuracy of the assessment system, but such a comparison still gives some understanding that the proposed system is working correctly. In order to conduct a complete verification of the system, it would be reasonable to assess several more certified green buildings in the Republic of Kazakhstan and compare the results.

Another critical parameter indicating the correct and accurate work of the assessment tool was the stability of the results obtained when buildings were assessed by different experts. The same building should ideally have the same rating regardless of who evaluated it. To check the stability parameter, Building Complex III, a residential complex in NurSultan, was evaluated by four different experts with different backgrounds and expertise levels during the study (Figure 5).

Figure 5 shows that three out of four assessments had very close results (66-68 points), and only one expert's (\#2) assessment (about 46 points) differed from the rest. However, although three out of four final assessments were close, the assessments of each category differed significantly; there was no unity and stability in them. Figure 6 shows the distribution of points within the categories. It can be seen that different researchers evaluated specific categories in entirely different ways. For example, the "sustainable building materials" category has the most significant standard deviation of 28.13 points; the maximum score in this category is 94 and the minimum is 33 , which is a massive spread for the same building and raises some doubts about the accuracy of its assessment. These results show that the assessment of existing buildings is mostly a case of having no reliable data and documents 
to check the parameters, e.g., the materials used, which resulted in different scores. In such cases, the assessment is entirely subjective to the assessing person, whose experience and knowledge are the factors affecting the objectivity of the assessment. However, in an ideal scenario, the assessment tool should create conditions for evident objectification, excluding the human factor and reducing possible personal variations. It was suggested to modify the existing criteria to make them more objective if there is no proper documentation and material information.

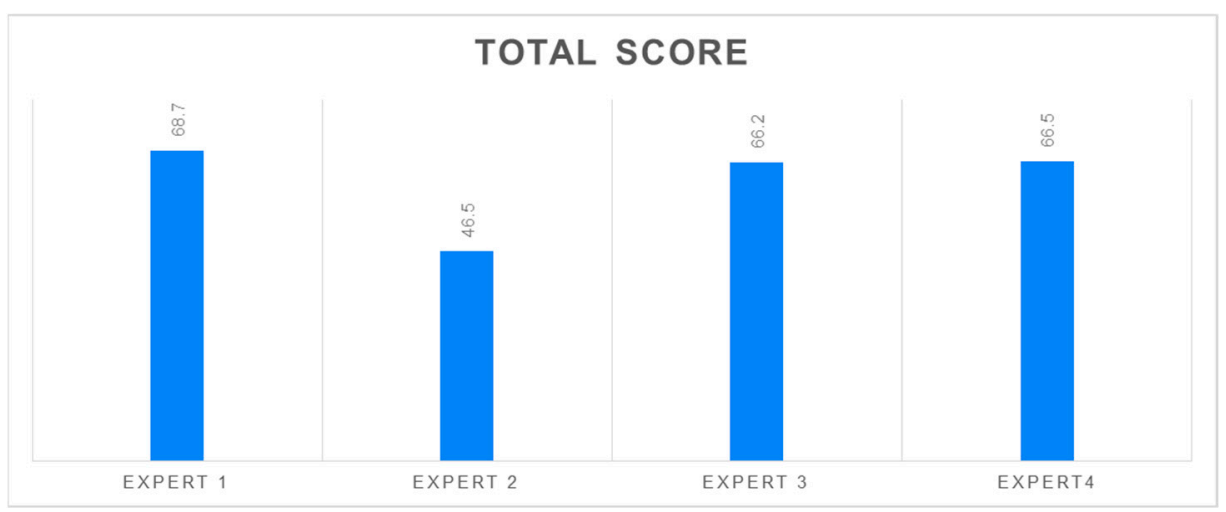

Figure 5. The total scores of Building Complex III given by four different experts.

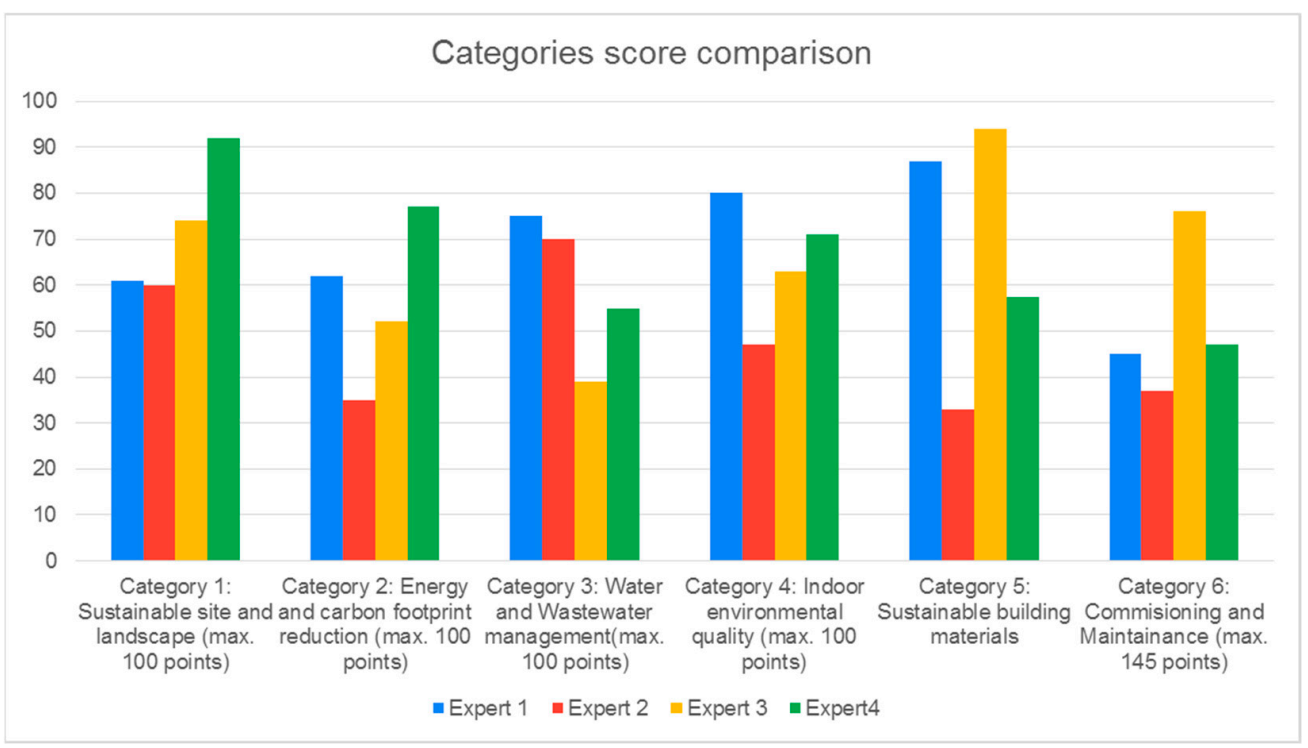

Figure 6. The "Green block" residential complex categories scores.

\subsection{Discussions of the Difficulties and Further Requirements}

The most critical issue in assessing the existing buildings to check their response levels to green building concepts was identified as the availability of information about the particular building assessed. One of the critical lessons learned from the current study was that abstract information is not good enough and is unreliable to assess accurately. Document-based information is needed for most cases. For example, it might not be enough to visit the building and collect information from the residents living in that building or even the constructors involved in the building process. For example, the materials used, energy-saving technologies, building performance, and even more information about the construction and commissioning progress should be evaluated based on the merit criteria using documentation or standard measurements only if the assessment does not aim to test satisfaction or user experiences. 
Another issue is how to deal with the situation if data or knowledge are not accessible or are unknown for particular criteria. A solution was suggested in the roundtable discussion: in the absence of information, not to award points. Thus, this suggestion aimed to eliminate all kinds of assumptions and inaccuracies. However, it was also found that this approach entails a possible decrease in the final scores, since it is highly likely to have some missing information for assessments of existing buildings. As a result, the high points awarded to buildings in the assessment stages are due to their characteristics and high performance and the availability of the necessary information about them.

A typical example is Building Complex II, which earned the highest score in our assessments due to being certified and having the data and the information required. Thus, the scores obtained by buildings in our research were the lowest possible. By providing the necessary information and a more detailed assessment, these same buildings would probably receive higher scores.

The foundational certification systems address buildings under construction, but this study assessed buildings already in operation. It would be more appropriate if ongoing projects were assessed, but this would have limited the study to only a few examples and extended the period of the case study assessments significantly.

This research also showed that, in general, any attempt to develop a set of criteria and assessment procedures should be tested in the field by performing assessments of different types of building in the targeted contexts. The questionnaire should be revised once again in order to exclude confusing questions. Perhaps at this stage, some simplification or reduction of the questionnaire is needed. It is necessary to make it as objective, understandable, and straightforward as possible; it should avoid difficult or impossible questions to yield clear answers whenever possible. It should focus on issues that do not require in-depth study and unavailable information for existing buildings. It could also either exclude questions regarding buildings under construction or separate the questionnaire and form two separate ones for buildings under construction and existing buildings.

\section{Conclusions and Future Recommendations}

The construction industry is a significant contributor to environmental deterioration. The green building concept is an essential innovative response to these challenges, associated with the broader aspects of sustainability considerations [24,25]. Therefore, the application of green building rating systems has attracted much attention at the scientific, government, and industry levels [25]. In Kazakhstan, perceptions of sustainability are still in the embryonic phase [1]. Despite the widespread adoption of green certification methodologies, the application of global certification systems in Kazakhstan is complicated due to the lack of knowledge and limited awareness.

The current study evaluated global certification systems' criteria on their adequacy in Kazakhstan's reality and set the ambitious goal of promoting green practices. A set of categories were scrutinized, and a newly developed tool was distributed among construction and green building experts for assessing residential and commercial buildings. This paper also identified particular challenges associated with green building certification in Kazakhstan, and a proper investigation of these challenges may develop solutions to implement green practices and promote sustainability in building construction. Although some existing buildings' properties, such as materials, cannot be improved, reconsidering existing water and energy systems and adding more greenery to the landscape will significantly contribute to environmental performance.

The "sustainable site and landscape" and "indoor environmental air quality" criteria obtained the highest scores, recognized as the most important. This result might be rooted in the existing perceptions of researchers in the context of individual preferences related to the quality of life, giving more points to the social aspects of the categories rather than environmental considerations. The "energy and carbon footprint reduction" and "water and wastewater management" criteria had the lowest importance. The main underlying reason was the low cost of energy and water in the country. Although resource-saving 
legislation and technologies have been incrementally introduced in the country, a lack of awareness and a failure to recognize the potential consequences of environmental pollution and resource depletion is still dominant. The "sustainable materials" category presented the most significant standard deviation value, varying from 94 to 33, indicating the low precision and reliability of the evaluation tool. Understanding the concept of sustainable materials is vague; for example, the utilization of materials with low embodied carbon is not widespread in the construction industry, and the link between the materials and carbon emissions is less well understood. All carbon emissions are associated with direct combustion activities. The significant score fluctuation was revealed in the same sample assessed on the same rating scale by several experts. This result showed the lack of cohesion within the expert group. It can also be explained by the ambiguity of the questions, for instance, the distance to amenities. This is a complex question that will not necessarily lead to objective estimates.

Green building rating systems contribute to buildings' performance in environmental aspects. They are widely accepted alongside incorporating the Life Cycle Assessment tool [26]. A consistent framework should be developed for analyzing the existing rating system and the applicability of the criteria to Kazakhstan's reality.

Although famous certification tools are currently working in the Kazakhstani market, they may not promote sustainability within the industry due to the high service costs and the lack of context-oriented criteria. The main contribution of this research was proving the necessity of developing an authentic tool that should be based on international standards and, at the same time, address country-level issues. The development of a reliable approach has significant importance in stimulating green building construction [25]. Moreover, such a tool should be simplified to eliminate the cost of training the experts or minimizing this cost. Raising awareness within the industry and promoting the implementation of sustainability considerations are recommended. Such a contribution to the environment and society would add value to the company's reputation.

Green building assessment tool development is a trigger point for reconsideration of existing resource utilization standards. For example, based on the data obtained from the existing buildings' performance evaluation, the outdated water management requirements established during the Soviet Union could be updated to comply with contemporary design. This particular example addresses water quality, which is low compared with developed countries' standards.

Author Contributions: Conceptualization, F.K., T.J., A.R., A.T., and Z.Y.; methodology, F.K., T.J., A.R., A.T., and Z.Y.; validation, F.K.; formal analysis, T.J., A.R., A.T., and Z.Y.; investigation, T.J., A.R., A.T., and Z.Y.; resources, F.K.; data curation, F.K., T.J., A.R., A.T., and Z.Y.; writing—original draft preparation, T.J., A.R., A.T., and Z.Y.; writing—review and editing, F.K.; visualization, A.R.; supervision, F.K.; project administration, F.K.; funding acquisition, F.K. All authors have read and agreed to the published version of the manuscript.

Funding: The authors acknowledge financial support from the Nazarbayev University Faculty's development competitive research grants (Funder Project Reference: 280720FD1904).

Conflicts of Interest: The authors declare no conflict of interest. The authors declare that they have no known competing financial interests or personal relationships that could have appeared to influence the work reported in this paper.

\section{References}

1. Akhanova, G.; Nadeem, A.; Kim, J.; Azhar, S. A multi-criteria decision-making framework for building sustainability assessment in Kazakhstan. Sustain. Cities Soc. 2020, 52, 101842. [CrossRef]

2. Akintayo, F.; Oyebade, O.; Songca, S.; Adebisi, N.; Oluwafemi, O.; Fadipe, O. Assessment of the impacts of building construction activities on the environment. Niger. J. Technol. 2020, 39, 325-331. [CrossRef]

3. OECD/IEA. World Energy Outlook; OECD/IEA: Paris, France, 2010.

4. Kim, Y.; Sun, C. The Energy-Efficient Adaptation Scheme for Residential Buildings in Kazakhstan. Energy Procedia 2017, 118, 28-34. [CrossRef] 
5. Karatayev, M.; Clarke, M. A review of current energy systems and green energy potential in Kazakhstan. Renew. Sustain. Energy Rev. 2016, 55, 491-504. [CrossRef]

6. Cole, L.; Coleman, S.; Scannell, L. Place attachment in green buildings: Making the connections. J. Environ. Psychol. 2021, 74, 101558. [CrossRef]

7. Ali, H.; Al Nsairat, S. Developing a green building assessment tool for developing countries—Case of Jordan. Build. Environ. 2009, 44, 1053-1064. [CrossRef]

8. Fowler, K.; Rauch, E. Sustainable Building Rating Systems Summary; Pacific Northwest National Lab.(PNNL): Richland, WA, USA, 2006; pp. 1-55.

9. McPartland, R.; McPartland, R.; Carson, J.; McPartland, R.; McPartland, R.; McPartland, R.; Beckinsale, E. What is Breeam? NBS 2021. Available online: https://www.thenbs.com/knowledge/what-is-breeam (accessed on 8 March 2021).

10. Liu, C.; Wang, F.; MacKillop, F. A critical discussion of the BREEAM Communities method as applied to Chinese eco-village assessment. Sustain. Cities Soc. 2020, 59, 102172. [CrossRef]

11. Usgbc. LEED rating system I US Green Building Council. 2021. Available online: https://www.usgbc.org/leed (accessed on 22 February 2021).

12. Greer, F.; Chittick, J.; Jackson, E.; Mack, J.; Shortlidge, M.; Grubert, E. Energy and water efficiency in LEED: How well are LEED points linked to climate outcomes? Energy Build. 2019, 195, 161-167. [CrossRef]

13. Say, C.; Wood, A. Sustainable rating systems around the world. Counc. Tall Build. Urban Habitat J. (CTBUH Rev.) 2008, 2, 18-29.

14. Pacetti, M. The Sustainable City VII; WIT Press: Southampton, UK, 2012.

15. Breeam. Scoring and Rating BREEAM Assessed Buildings. 2021. Available online: https://www.breeam.com/BREEAM201 1SchemeDocument/Content/03_ScoringRating/scoring.htm (accessed on 11 February 2021).

16. Mattoni, B.; Guattari, C.; Evangelisti, L.; Bisegna, F.; Gori, P.; Asdrubali, F. Critical review and methodological approach to evaluate the differences among international green building rating tools. Renew. Sustain. Energy Rev. 2018, 82, 950-960. [CrossRef]

17. Shan, M.; Hwang, B. Green building rating systems: Global reviews of practices and research efforts. Sustain. Cities Soc. 2018, 39, 172-180. [CrossRef]

18. Awadh, O. Sustainability and green building rating systems: LEED, BREEAM, GSAS and Estidama critical analysis. J. Build. Eng. 2017, 11, 25-29. [CrossRef]

19. Ibec. Graphic Indication System of the Rating Results. 2021. Available online: https://www.ibec.or.jp/CASBEE/english/ graphicE.htm (accessed on 15 February 2021).

20. Greenglobes. Building Environmental Assessments-Welcome. 2021. Available online: http://www.greenglobes.com/home.asp (accessed on 19 February 2021).

21. Kubba, S. Handbook of Green Building Design and Construction; Elsevier Science and Technology Books, Inc.: Oxford, UK, 2017.

22. Usgbc. The Green Home Advantage LLC I U.S. Green Building Council. 2021. Available online: https://www.usgbc.org/ organizations/green-home-advantage-1lc?view=overview (accessed on 22 February 2021).

23. Cawater-info. Report of the Republic of Kazakhstan. 2021. Available online: http://www.cawater-info.net/5wwf/national_ report_kazakhstan_e.htm (accessed on 28 February 2021).

24. Khan, J.; Zakaria, R.; Shamsudin, S.; Abidin, N.; Sahamir, S.; Abbas, D.; Aminudin, E. Evolution to Emergence of Green Buildings: A Review. Adm. Sci. 2019, 9, 6. [CrossRef]

25. Li, Y.; Chen, X.; Wang, X.; Xu, Y.; Chen, P. A review of studies on green building assessment methods by comparative analysis. Energy Build. 2017, 146, 152-159. [CrossRef]

26. Sartori, T.; Drogemuller, R.; Omrani, S.; Lamari, F. A schematic framework for Life Cycle Assessment (LCA) and Green Building Rating System (GBRS). J. Build. Eng. 2021, 38, 102180. [CrossRef] 